\title{
Early Mobilization in Ischemic Stroke: A Pilot Randomized Trial of Safety and Feasibility in a Public Hospital in Brazil
}

\author{
Simone Rosa Poletto ${ }^{a}$ b Letícia Costa Rebello ${ }^{a}$ \\ Maria Júlia Monteiro Valença ${ }^{a}$ Daniele Rossato ${ }^{a}$ \\ Andrea Garcia Almeida ${ }^{a}$ b Rosane Brondani ${ }^{a}$ \\ Márcia Lorena Fagundes Chaves ${ }^{a}$ Luiz Antônio Nasi ${ }^{a}$ \\ Sheila Cristina Ouriques Martins ${ }^{a, b}$ \\ ${ }^{a}$ Hospital de Clínicas de Porto Alegre, and b ${ }^{b}$ Hospital Moinhos de Vento, Porto Alegre, Brazil
}

Key Words

Stroke $\cdot$ Rehabilitation $\cdot$ Physical therapy $\cdot$ Early mobilization

\section{Abstract}

Background: The effect of early mobilization after acute stroke is still unclear, although some studies have suggested improvement in outcomes. We conducted a randomized, single-blind, controlled trial seeking to evaluate the feasibility, safety, and benefit of early mobilization for patients with acute ischemic stroke treated in a public teaching hospital in Southern Brazil. This report presents the feasibility and safety findings for the pilot phase of this trial. Methods: The primary outcomes were time to first mobilization, total duration of mobilization, complications during early mobilization, falls within 3 months, mortality within 3 months, and medical complications of immobility. We included adult patients with CT- or MRI-confirmed ischemic stroke within $48 \mathrm{~h}$ of symptom onset who were admitted from March to November 2012 to the acute vascular unit or general emergency unit of a large urban emergency department (ED) at the Hospital de Clínicas de Porto Alegre. The severity of the neurological deficit on admission was assessed by the National Institutes of Health Stroke Scale (NIHSS). The NIHSS and modified Rankin Scale (mRS, functional outcome) scores were assessed on day 14 or at discharge as well as at 3 months. Activities of daily living (ADL) were measured with the modified Barthel Index (mBI) at 3 months. Results: Thirty-seven patients (mean age 65 years, mean NIHSS score 11) were randomly allocated to an intervention group (IG) or a control group (CG). The IG received earlier $(p=0.001)$ and more frequent $(p<0.0001)$ mobilization than the CG. Of the 19 patients in the CG, only 5 (26\%) underwent a physical therapy program during hospitalization. No complications (symptomatic hypotension or worsening of neuro- 
logical symptoms) were observed in association with early mobilization. The rates of complications of immobility (pneumonia, pulmonary embolism, and deep vein thrombosis) and mortality were similar in the two groups. No statistically significant differences in functional independence, disability, or ADL ( $\mathrm{mBI} \geq 85$ ) were observed between the groups at the 3-month follow-up. Conclusions: This pilot trial conducted at a public hospital in Brazil suggests that early mobilization after acute ischemic stroke is safe and feasible. Despite some challenges and limitations, early mobilization was successfully implemented, even in the setting of a large, complex ED, and without complications. Patients from the IG were mobilized much earlier than controls receiving the standard care provided in most Brazilian hospitals.

(c) 2015 S. Karger AG, Basel

\section{Introduction}

Stroke is the second leading cause of death and the leading cause of disability worldwide [1-4]. One year after a stroke, one third of patients will die and one third will be unable to perform activities of daily living (ADL) [5]. In the first 30 days, approximately $50 \%$ of the deaths are directly due to stroke, whereas the other $50 \%$ are due to complications caused by immobility (pneumonia and venous thromboembolism) [6].

Treatment in a stroke unit, with a standardized set of actions performed by an interdisciplinary team, is highly effective in reducing disability and is the only factor which demonstrably impacts mortality [7-9]. However, uncertainty remains as to which individual aspects are responsible for this benefit. Rehabilitation is an important component, especially early mobilization with out-of-bed activity, which potentially reduces complications due to immobility $[9,10]$.

Several guidelines recommend starting physical therapy as soon as possible [11, 12], once a patient is stable. However, the optimal timing remains unknown [8]. Doubts remain about the effect of early mobilization in decreasing cerebral blood flow in the penumbral area $[13,14]$ and regarding the interruption of vital sign monitoring, especially in patients who received thrombolysis. Clinical trials with small samples were conducted and yielded conflicting results [15-17].

Brazil is the only country with more than 100 million inhabitants that offers free health care to its entire population. However, the quality of care remains poor, especially in the rehabilitation field. This is due to a lack of human resources in hospitals, a lack of dedicated stroke units, and a dearth of literature to support a change in care via policymaking [18].

In 2012, the Brazilian Ministry of Health launched a new policy to encourage the organization of acute and rehabilitative stroke care [19]. Hospitals with organized stroke units, including thrombolytic therapy and interdisciplinary teams, were allocated greater resources to serve these patients. However, due to the high incidence of stroke and the need for better resource use in the public health system, it is essential that the effectiveness of different stroke unit interventions be demonstrated, especially in the rehabilitation field.

To evaluate the benefit of early mobilization after ischemic stroke, we conducted a randomized clinical trial (RCT) comparing this treatment, initiated within $48 \mathrm{~h}$ of stroke, versus routine physical therapy as usually provided at the study facility (standard care). This pilot study sought to establish the feasibility and safety of early mobilization for patients with acute ischemic stroke treated in a public teaching hospital in Southern Brazil, controlling for stroke treatment (with thrombolytic drugs).

Our main goals were (1) to evaluate the feasibility of early and frequent mobilization in this setting and (2) to evaluate the safety of early mobilization, with no increases in medical complications or adverse events compared with routine physical therapy. 


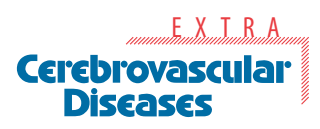

\begin{tabular}{l|l}
\hline \multicolumn{2}{l}{ Cerebrovasc Dis Extra 2015;5:31-40 } \\
\hline DOI: $10.1159 / 000381417$ & $\begin{array}{l}\text { C } 2015 \text { S. Karger AG, Basel } \\
\text { www.karger.com/cee }\end{array}$ \\
\hline Poletto et al.: Early Mobilization in Ischemic Stroke: A Pilot Randomized Trial of Safety
\end{tabular} Poletto et al.: Early Mobilization in Ischemic
and Feasibility in a Public Hospital in Brazil

\section{Subjects and Methods}

This randomized, controlled, single-blind clinical trial (ClinicalTrials.gov No. NCT01694992) compared early mobilization (within $48 \mathrm{~h}$ of symptom onset) with routine physical therapy, with mortality, morbidity, and functional status as the main outcomes. In this pilot study, we present the results of a feasibility and safety analysis of this intervention and describe the characteristics of the routine physical therapy provided in our facility to compare it with the proposed intervention.

\section{Population}

We included adult patients with CT- or MRI-confirmed ischemic stroke within $48 \mathrm{~h}$ of symptom onset who were admitted on weekdays from March to November 2012 to the acute vascular unit (AVU) or general emergency unit of a large urban emergency department (ED). The additional inclusion criteria were: clinical and hemodynamic stability (systolic blood pressure 120-220 mm Hg, $\mathrm{SaO}_{2}>92 \%$ with or without supplementation, heart rate 60-100 bpm, body temperature $<38^{\circ} \mathrm{C}$, and respiratory rate $<25$ ); Glasgow Coma Scale score $>8$; modified Rankin Scale (mRS) [20] score $\leq 3$, and motor deficit and/or ataxia as measured by the National Institutes of Health Stroke Scale (NIHSS) [20]. Exclusion criteria were: hemorrhagic stroke or transient ischemic attack, history of progressive neurological disease, acute coronary disease, decompensated cardiac disease, or respiratory failure.

\section{Study Site}

The study was conducted at the Hospital de Clínicas de Porto Alegre (HCPA), a public university hospital in Southern Brazil. After initial assessment by an emergency physician, all stroke patients were evaluated by a stroke neurologist, using a previously established protocol, and were followed by the stroke team from the emergency room to hospital discharge. Whenever possible, patients were admitted to the AVU, a physical area inside the ED with nine monitored beds and staff trained to treat all acute vascular diseases including stroke, acute coronary syndrome, pulmonary embolism, and acute aortic conditions. This unit is supported by neurology residents and stroke neurologists $24 \mathrm{~h}$ a day. When there were no beds available in the AVU, less severely afflicted patients were treated in the general emergency area. After stabilization, patients were moved from the AVU to the general emergency area and from there transferred to inpatient units.

\section{Procedures}

Randomization was performed online (http://randomization.com) by a study investigator, using a randomization plan stratified by blocks of varying sizes (blocks of 2, 4, or 6). After obtaining informed consent, the patients were randomly allocated to an intervention group (IG) or a control group (CG), with the allocation records stored in opaque, sealed, and sequentially numbered envelopes.

\section{Intervention}

Patients randomized to the IG received early mobilization, which was started within 48 $\mathrm{h}$ of stroke symptom onset. The program was carried out by trained physical therapists, and focused on sitting out of bed in a chair or standing (whenever and as soon as possible) and conducting functional training and motor relearning, pursuant to the Bobath concept [21]. Exercises were performed bilaterally with at least 5 repetitions for each joint and each exercise and emphasis on deficits in the impaired side [22]. In addition, patients and their families received a manual developed for the study, with guidance on positioning in bed and posture shifting to use at home after discharge. IG patients were mobilized 5 times a week, 
once a day, for approximately $30 \mathrm{~min}$ per session, in addition to sitting out of bed for at least 30 min whenever possible. The session duration (in minutes) and number of sessions were recorded. Sessions were held until hospital discharge or the 14th treatment day, whichever occurred first, regardless of where the patient was located.

Patients randomized to the $C G$ received standard care, with conventional physical therapy performed when requested by the staff. Therapy varied according to the patients' needs and the availability of physical therapists but generally included global motor exercises and respiratory therapy (ordinarily in bed). The duration of standard-care therapy sessions was approximately $15 \mathrm{~min}$. The mobilization time (in minutes) and number of sessions (only motor activities) were also recorded for this group.

\section{Blinding}

Patients were informed that they would begin physical therapy on the first day of assessment (IG) or follow the hospital routine (CG). Baseline and postintervention measures were performed by a study investigator who remained blinded to group allocation. To ensure blinding of any monitoring neurologists, no notes of group allocation were made in the hospital's electronic medical record.

\section{Patient Evaluation}

The severity of the neurological deficit on admission was assessed by the NIHSS. Outcome measures were evaluated by a neurologist blinded to the intervention. NIHSS and mRS (functional outcome) scores were assessed on day 14 or at discharge, whichever occurred first, and at 3 months. ADL were measured by the modified Barthel Index (mBI) [23] at 3 months.

Demographic characteristics and clinical data (risk factors, clinical findings, prior mRS score, NIHSS score, stroke characteristics and treatment, treatment duration, and general complications of stroke) were collected, as were the time from symptom onset to first mobilization, total duration of mobilization, and factors restricting mobilization. Procedure-related adverse events [symptomatic hypotension (presyncope or syncope) and worsening of neurological deficits during physical therapy] were recorded, as was the frequency of falls during hospitalization and within 3 months of stroke.

\section{Outcome Measures}

The primary outcome measures of the RCT were functional capacity (mRS score $0-2$ ) and mortality at 3 months. In this pilot study, we sought only to evaluate the feasibility and safety of the intervention.

The primary feasibility endpoints were (a) time to first mobilization and (b) total duration of motor physical therapy. The primary safety endpoints were: (a) complications during early mobilization (first $48 \mathrm{~h}$ ), i.e. symptomatic hypotension (syncope or presyncope) or neurological deterioration (defined as any worsening in NIHSS score); (b) falls during hospitalization and within 3 months of stroke; (c) complications related to immobility (pneumonia, pulmonary embolism, and deep vein thrombosis) at 3 months, and (d) death within 3 months. Secondary outcomes were measured at 3 months, i.e. mRS score $0-1$, mRS score $0-2$, mean NIHSS score, and $\mathrm{mBI} \geq 85$.

\section{Statistical Analysis}

The sample size calculated for the RCT was 164 patients (82 per group), with 80\% power and a significance level of $5 \%$ to find a $20 \%$ difference in functional status between the groups. For this pilot study, we estimated that $\geq 20$ patients would be required to detect a doubling of mobilization time with $80 \%$ power at the $5 \%$ level. 
Poletto et al.: Early Mobilization in Ischemic Stroke: A Pilot Randomized Trial of Safety and Feasibility in a Public Hospital in Brazil

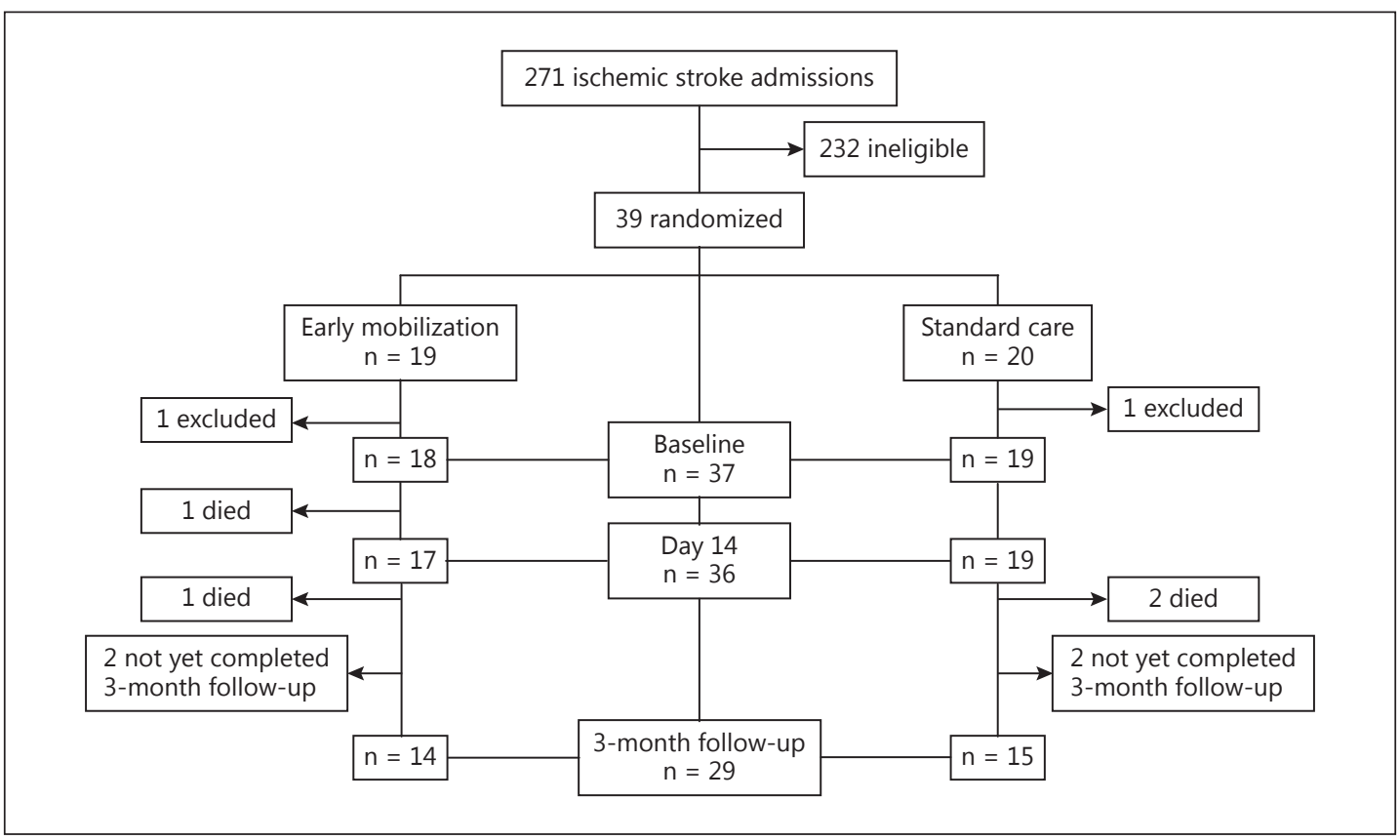

Fig. 1. Patient selection and intervention flowchart for the study.

Quantitative data are presented as means (SD) for normally distributed variables and medians (IQR) for nonparametric variables, and they were compared using Student's test and the Mann-Whitney U test, respectively. Categorical variables are expressed as proportions, and they were compared by $\chi^{2}$ or Fisher's exact test, as appropriate. Logistic regression analysis was used to investigate whether the intervention influenced stroke outcomes at 3 months (adjusted for premorbid mRS score, age, and NIHSS score). All analyses were performed in SPSS for Windows 16.0.

\section{Ethical Aspects}

The study was approved by the HCPA Research Ethics Committee and is registered in ClinicalTrials.gov under the identification No. NCT01694992.

\section{Results}

During the recruitment phase, 271 patients with ischemic stroke were admitted to the HCPA ED. Of these, 232 did not meet the inclusion criteria. Late hospital arrival $(>48 \mathrm{~h}$ since symptom onset) was the main cause of exclusion.

Thirty-seven patients were studied: 18 in the IG (early mobilization) and 19 in the CG (standard care). The study flowchart is shown in figure 1 . The demographic and clinical characteristics were similar in both groups (table 1). A trend toward a higher prevalence of diabetes was observed in the controls. In both groups, $94 \%$ of the participants were white. On admission, 6 patients had a preexisting $m R S$ score $>1$ ( 4 in the IG and 2 in the CG, $p=0.66$ ). Six patients in the IG and 3 controls already had impaired mobilization prior to stroke due to COPD, gonarthrosis, recent hip osteosynthesis, brachial plexus injury, and congestive heart failure. Of the 37 stroke patients, 13 received thrombolysis ( 6 in the IG and 7 of the controls). 


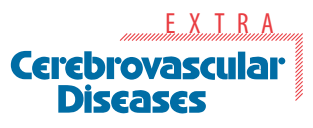

Table 1. Clinical and demographic features of the IG and CG \begin{tabular}{l|l}
\hline Cerebrovasc Dis Extra 2015;5:31-40 \\
\hline DOI: $10.1159 / 000381417$ & $\begin{array}{l}\text { C } 2015 \text { S. Karger AG, Basel } \\
\text { www.karger.com/cee }\end{array}$ \\
\hline Poletto et al.: Early Mobilization in Ischemic Stroke: A Pilot Randomized Trial of Safety
\end{tabular} Poletto et al:. Early Mobilization in Ischemic
and Feasibility in a Public Hospital in Brazil

\begin{tabular}{|c|c|c|c|}
\hline & $\begin{array}{l}\mathrm{IG} \\
(\mathrm{n}=18)\end{array}$ & $\begin{array}{l}\text { CG } \\
(n=19)\end{array}$ & $\mathrm{p}$ value \\
\hline \multicolumn{4}{|l|}{ Demographic features } \\
\hline Age, years & $64 \pm 18$ & $66 \pm 16$ & 0.76 \\
\hline Female sex & $12(67)$ & $12(63)$ & 0.82 \\
\hline \multicolumn{4}{|l|}{ Stroke risk factors } \\
\hline Hypertension & $13(72)$ & $14(74)$ & 0.92 \\
\hline Diabetes & $2(11)$ & 7 (37) & 0.07 \\
\hline Hypercholesterolemia & $4(22)$ & $2(11)$ & 0.12 \\
\hline Smoking & 7 (28) & $6(26)$ & 0.79 \\
\hline $\mathrm{CHF}$ & $4(22)$ & $4(21)$ & 0.93 \\
\hline Ischemic heart disease & $3(17)$ & $4(21)$ & 0.73 \\
\hline Atrial fibrillation & $3(17)$ & $5(26)$ & 0.69 \\
\hline Obesity & $4(22)$ & $2(11)$ & 0.41 \\
\hline Sedentary lifestyle & $17(94)$ & $17(90)$ & 1.00 \\
\hline Previous stroke or TIA & $5(28)$ & $2(11)$ & 0.18 \\
\hline Premorbid mRS score & & & 0.66 \\
\hline 1 & $2(11)$ & $1(5)$ & \\
\hline 2 & $1(6)$ & 0 & \\
\hline 3 & $1(6)$ & $1(5)$ & \\
\hline Baseline NIHSS score & $10 \pm 7$ & $11 \pm 6$ & 0.71 \\
\hline Mild (0-5) & 6 & 5 & \\
\hline Moderate (6-11) & 6 & 6 & \\
\hline Moderately severe $(12-18)$ & 3 & 6 & \\
\hline Severe $(>18)$ & 3 & 2 & \\
\hline \multicolumn{4}{|l|}{ Stroke location and subtype } \\
\hline Stroke side (left) & $13(68)$ & $9(47)$ & 0.25 \\
\hline Anterior circulation & $15(82)$ & $14(83)$ & 0.39 \\
\hline Factors limiting mobilization & $6(33)$ & $3(16)$ & 0.27 \\
\hline Respiratory & 2 & 1 & \\
\hline Lower limb & 1 & 1 & \\
\hline Upper limb & 1 & 0 & \\
\hline Other $(\mathrm{CHF})$ & 2 & 1 & \\
\hline Thrombolytic treatment & $6(33)$ & $7(37)$ & 0.82 \\
\hline
\end{tabular}

Results are expressed as $\mathrm{n}(\%)$ or means \pm SD. TIA $=$ Transient ischemic attack; $\mathrm{CHF}=$ congestive heart failure.

\section{Primary Outcomes}

Feasibility

IG patients received mobilization earlier and more frequently than controls (table 2). The median time from stroke to first mobilization was $43 \mathrm{~h}$ (vs. $72 \mathrm{~h}$ in the CG), and the total duration of mobilization during the hospitalization period was $135 \mathrm{~min}$ [IQR 85-213; vs. 0 min in the CG (IQR 0-50)]. Only 2 patients did not initiate early mobilization (within $48 \mathrm{~h}$ ) in the IG. Moreover, only 5 patients in the CG (26\%) received physical therapy during hospitalization, with an average duration of 15 min per session. After hospital discharge, $57 \%$ of the patients in the IG and 37\% in the CG underwent physical therapy sessions ( $p=0.28)$. IG patients had more out-of-bed activities as compared with controls, initiating activities while still in the ED. Only the 5 patients who received physical therapy in the CG left their beds; all other controls remained bedbound during hospitalization.

\section{Safety}

There were no complications associated with early mobilization. No falls were recorded in either group within 3 months. 
Table 2. Mobilization measures

\begin{tabular}{|c|c|c|c|}
\hline & $\begin{array}{l}\text { IG } \\
(n=18)\end{array}$ & $\begin{array}{l}C G \\
(n=19)\end{array}$ & $\mathrm{p}$ value \\
\hline Time from stroke onset to first mobilization, $\mathrm{h}$ & $43(28-48)$ & $72(61-108)$ & 0.001 \\
\hline Total duration of mobilization, min & $135(85-213)$ & $0(0-50)$ & $<0.0001$ \\
\hline Physical therapy sessions, $\mathrm{n}$ & $4.5(3-7)$ & $0(0-3)$ & $<0.0001$ \\
\hline Out-of-bed activities, $\mathrm{n}$ & $4.2 \pm 2.3$ & $0.26 \pm 0.73$ & $<0.0001$ \\
\hline Out-of-bed activities in ED, $\mathrm{n}$ & $2.6 \pm 1.9$ & $0.21 \pm 0.53$ & $<0.0001$ \\
\hline
\end{tabular}

Results are expressed as medians (IQR) or means \pm SD.

Table 3. Clinical outcomes in the IG versus the CG

\begin{tabular}{|c|c|c|c|}
\hline & $\begin{array}{l}\text { IG } \\
(n=18 / 16)^{a}\end{array}$ & $\begin{array}{l}\text { CG } \\
(n=19 / 17)^{a}\end{array}$ & $\mathrm{p}$ value \\
\hline \multicolumn{4}{|l|}{ Complications at 3 months } \\
\hline Pneumonia & $3(18 \%)$ & $2(12 \%)$ & 0.5 \\
\hline Deep venous thrombosis & 0 & 0 & \\
\hline Pulmonary embolism & 0 & 0 & \\
\hline Mortality at 3 months & $2(13 \%)$ & $2(12 \%)$ & 0.68 \\
\hline \multicolumn{4}{|l|}{ Neurological impairment } \\
\hline \multicolumn{4}{|l|}{ NIHSS score } \\
\hline On admission & $10 \pm 7$ & $11 \pm 6$ & 0.71 \\
\hline At 14 days & $7 \pm 5.8$ & $10 \pm 7$ & 0.20 \\
\hline At 3 months & $5.1 \pm 6.3$ & $5.5 \pm 4.3$ & 0.84 \\
\hline \multicolumn{4}{|l|}{$\mathrm{mRS}$} \\
\hline mRS score $0-1$ at 3 months & $4 / 16(25 \%)$ & $1 / 17(6 \%)$ & 0.33 \\
\hline \multicolumn{4}{|l|}{ mRS score $0-1$ at 3 months } \\
\hline (excluding previous mRS scores $>0$ ) & $4 / 12(33 \%)$ & $1 / 15(7 \%)$ & 0.08 \\
\hline mRS score $0-2$ at 3 months & $8 / 16(50 \%)$ & $9 / 17(53 \%)$ & 0.87 \\
\hline \multicolumn{4}{|l|}{$\mathrm{mBI}$} \\
\hline At 3 months & $85(30-100)$ & $80(65-90)$ & 0.51 \\
\hline $\mathrm{mBI} \geq 85$ & $8 / 14(57 \%)$ & $7 / 15(47 \%)$ & 0.60 \\
\hline $\mathrm{mBI} \geq 85$ (excluding previous mRS scores $>0$ ) & $7 / 11(64 \%)$ & $6 / 13(46 \%)$ & 0.39 \\
\hline \multicolumn{4}{|l|}{ Resource use } \\
\hline Intensive care unit hospitalization & $2(11 \%)$ & $2(11 \%)$ & 0.68 \\
\hline Length of hospital stay, days & $8(5-14)$ & $10(4-25)$ & 0.66 \\
\hline
\end{tabular}

Results are expressed as means \pm SD or medians (IQR), unless indicated otherwise. ${ }^{\text {a }}$ At 14 days/at 3 months.

Clinical outcome results are presented in table 3. The proportion of patients who experienced immobility-related complications (pneumonia, pulmonary embolism, and deep vein thrombosis) within 3 months of stroke was similar in both groups, as was 3-month mortality.

\section{Secondary Outcomes}

No significant between-group differences were observed in functional independence (mRS score $0-2$ ), minimal or no disability (mRS score $0-1$ ), or NIHSS score at 14 days and 3 months (table 3). On analysis of functional recovery at 3 months, excluding patients with a previous 
mRS score $>0$, the frequency of an mRS score of $0-1$ was $33 \%$ among IG patients versus $7 \%$ among CG patients $(\mathrm{p}=0.08)$. At 3 months, both groups had similar median mBIs, as well as a similar proportion of patients with an $\mathrm{mBI} \geq 85$ (mild dependence or independence). No secondary outcome measure was significantly associated with group allocation in the logistic regression model controlling for baseline age, NIHSS score, and premorbid mRS score.

\section{Discussion}

The primary objective of this pilot study was achieved by demonstrating that early mobilization (within 24-48 h of stroke) is feasible and safe in the ED setting. Its safety was confirmed by the absence of symptomatic hypotension, neurological deterioration, or excess mortality in the IG.

The average monthly patient enrollment was higher than in other trials of early mobilization [16-18], showing the feasibility of such a study in a large hospital with several clinical trials running concomitantly. Early mobilization, including out-of-bed activity, was made possible by adapting the AVU (adding an armchair) and obtaining nurse and physical therapy staff support for the trial.

\section{Primary Outcomes}

\section{Feasibility}

Three phase II RCTs have evaluated early mobilization (within $24 \mathrm{~h}$ ) after acute stroke. The AVERT II in Australia ( $\mathrm{n}=71$ ) [15] and the VERiTAS study in the UK ( $\mathrm{n}=32$ ) [16] evaluated the safety and feasibility of early mobilization started within $24 \mathrm{~h}$ of stroke. The Norwegian AKEMIS $(n=56)$ [17] compared mobilization started within 24 h versus mobilization started at 24-48 h. In all three studies, all controls received daily physical therapy. Treatment group patients in the AVERT and the VERiTAS study also performed early, daily out-of-bed activities several times a day. In our study, the standardized program for the IG patients included daily physical therapy sessions (leaving the bed and early walking) started at 24-48 h, while the controls (who represented routine care at our hospital) received no routine physical therapy, except in the case of ventilatory complications or more severe stroke. Most patients in the CG did not leave their beds. Although Australia has well-organized stroke care, an observational study conducted in 5 stroke units showed that only $28 \%$ of acute stroke patients sat out of bed and only $13 \%$ performed some activity that could prevent complications and improve mobility and function [24].

The time to first mobilization was significantly shorter in the IG [ $43 \mathrm{~h}$ (IQR 28-48) vs. 72 h (IQR 61-108), $p=0.0001$ ], as shown in previous RCTs (AVERT: 18.1 vs. $30.8 \mathrm{~h}$; VERiTAS: 27.3 vs. $32 \mathrm{~h}$; AKEMIS: 13.1 vs. $33.3 \mathrm{~h}$ ). The number of sessions and the length of therapy were also greater in the IG. However, unlike the early mobilization protocol used in the AVERT, where treatment group patients were mobilized 3-4 times daily, the IG patients in our study were mobilized only once a day, due to staffing issues at our hospital.

\section{Safety}

Like the present study, previous investigations have demonstrated that early mobilization after stroke does not cause symptomatic hypotension, probably due to an increase in sympathetic response generated by the stress of ischemia [25]. As in other RCTs, there was no increased risk of falls $[15,16]$. No patient had any deterioration of neurological deficit during treatment. Although reduced cerebral perfusion in the penumbral area and reduced blood flow velocity may occur when a patient is placed early in the sitting position [26], there is no scientific evidence that this affects functional outcomes. 
There is no proven association between early mobilization and fewer complications secondary to immobility $[10,27]$. We found similar results in both groups, as did the AKEMIS and the AVERT. Conversely, in the VERiTAS study, patients receiving the intervention had fewer complications. Diserens et al. [28] also found a significant reduction in the number of severe complications in patients receiving treatment ( $52 \mathrm{~h}$ after stroke onset) compared with controls.

Mortality was similar in both groups, indicating that early mobilization within $24-48 \mathrm{~h}$ of stroke is safe, as observed in other RCTs [15-17].

\section{Secondary Outcomes}

The proportion of patients with mRS scores of $0-2$, the degree of ADL dependence, and the degree of neurological deficit were similar in both groups. When excluding patients with prior impairment, there was a trend toward better functional outcomes in the IG; however, this pilot study was underpowered to evaluate whether early mobilization resulted in better neurological outcomes. Inclusion of patients with prior disabilities may have contributed to worse functional outcomes at 3 months. These findings are similar to those of previous studies $[15,16]$ that evaluated these outcomes in small samples.

\section{Limitations}

The main limitation of this trial is the small sample, which reduces the statistical power needed to demonstrate the effect of the intervention. Nonetheless, these pilot results reinforce the safety and feasibility of early mobilization, which may help further development of the main RCT. Another limitation is the inclusion of patients from both the AVU and the general ED, since patients may not be monitored as carefully in the general emergency area as in the AVU. However, this was representative of reality, as most stroke care in the country is still provided in general wards. Another concern was the lower amount and frequency of physical therapy in the IG, which differed substantially from other RCTs. Because of structural institutional challenges, not all patients were able to leave bed or walk early, even though outof-bed activities were prioritized in the IG.

\section{Conclusion}

Early mobilization is a simple intervention that may be performed by a physical therapist, aided by multiple members of the stroke team, but its feasibility, safety, and effectiveness must be established. Although this study was unable to prove the effectiveness of this intervention, it corroborated previous safety and feasibility findings. Despite some challenges and limitations, early mobilization was successfully implemented, even in the setting of a large, complex ED, and without complications; patients from the IG were mobilized much earlier than the controls receiving the standard care provided in most Brazilian hospitals. Finally, this study helped consolidate a change in routine care at the HCPA, with rehabilitation practices adapted to the reality of public health in Brazil.

\section{Acknowledgements}

We thank the AVU and ED patients and staff who made this study possible. The HCPA Research and Event Incentive Fund (FIPE) provided financial support. Neither funder had any involvement in the planning, conduct, or reporting of this trial. 
Poletto et al.: Early Mobilization in Ischemic Stroke: A Pilot Randomized Trial of Safety and Feasibility in a Public Hospital in Brazil

\section{References}

1 Pontes-Neto OM, Silva GS, Feitosa MR, et al: Stroke awareness in Brazil: alarming results in a community based study. Stroke 2008;39:292-296.

2 Lopez AD, Mathers CD, Ezzati M, Jamison DT, Murray CJ: Global and regional burden of diseases and risk factors, 2001: systematic analysis of population health data. Lancet 2006;367:1747-1757.

-3 Bonita R, Mendis S, Truelsen T, Bogousslavsky J, Toole J, Yatsu F: The Global Stroke Initiative. Lancet Neurol 2004;3:391-393.

4 Lavados PM, Hennis AJ, Fernandes JG, et al: Stroke epidemiology, prevention, and management strategies at a regional level: Latin America and the Caribbean. Lancet Neurol 2007;6:362-372.

5 Thrift AG, Dewey HM, Macdonell RAL, McNeil JJ, Donnan GA: Stroke incidence on the east coast of Australia: the North East Melbourne Stroke Incidence Study (NEMESIS). Stroke 2000;31:2087-2092.

6 Bamford J, Dennis M, Sandercock P, et al: The frequency, causes and timing of death within 30 days of a first stroke: the Oxfordshire Community Stroke Project. J Neurol Neurosurg Psychiatry 1990;53:825-829.

7 Stroke Unit Trialists' Collaboration: Organized inpatient (stroke unit) care for stroke. Cochrane Database Syst Rev 2007;4:CD000197.

8 Bernhardt J, Indredavik B, Langhorne P: When should rehabilitation begin after stroke? Int J Stroke 2013;8:5-7.

-9 Duncan PW, Zorowitz R, Bates B, Choi JY, Glasberg JJ, Graham GD, et al: Management of Adult Stroke Rehabilitation Care: a clinical practice guideline. Stroke 2005;36:e100-e143.

10 Indredavik B, Bakke F, Slørdahl SA, Rokseth R, Håheim LL: Treatment in a combined acute and rehabilitation stroke unit: which aspects are most important? Stroke 1999;30:917-923.

-11 Adams HP Jr, del Zoppo G, Alberts MJ, et al: Guidelines for the early management of adults with ischemic stroke: a guideline from the American Heart Association/American Stroke Association Stroke Council, Clinical Cardiology Council, Cardiovascular Radiology and Intervention Council, and the Atherosclerotic Peripheral Vascular Disease and Quality of Care Outcomes in Research Interdisciplinary Working Groups: the American Academy of Neurology affirms the value of this guideline as an educational tool for neurologists. Stroke 2007;38:1655-1711.

-12 European Stroke Organization (ESO) Executive Committee; ESO Writing Committee: Guidelines for management of ischemic stroke and transient ischemic attack. Cerebrovasc Dis 2008;25:457-507.

13 Diserens K, Michel P, Bogousslavsky J: Early mobilisation after stroke: review of the literature. Cerebrovasc Dis 2006;22:183-190.

14 Wojner-Alexander AW, Garami Z, Chernyshev OY, Alexandrov AV: Heads down: flat positioning improves blood flow velocity in acute ischemic stroke. Neurology 2005;64:1354-1357.

-15 Bernhardt J, Dewey H, Thrift A, Collier J, Donnan G: A Very Early Rehabilitation Trial for Stroke (AVERT) phase II safety and feasibility. Stroke 2008;39:390-396.

$\checkmark 16$ Langhorne P, Stott D, Knight A, Bernhardt J, Barer D, Watkins C: Very Early Rehabilitation or Intensive Telemetry after Stroke: a pilot randomised trial. Cerebrovasc Dis 2010;29:352-360.

-17 Sundseth A, Thommessen B, Rønning OM: Outcome after mobilization within 24 hours of acute stroke: a randomized controlled trial. Stroke 2012;43:2389-2394.

18 Ministério da Saúde: DATASUS. http://tabnet.datasus.gov.br/cgi/deftohtm.exe?idb2010/c08.def (accessed August 20, 2012).

19 Ministério da Saúde: Portaria 665 de 12 de Abril de 2012. Dispõe sobre os critérios de habilitação dos estabelecimentos hospitalares como Centro de Atendimento de Urgência aos Pacientes com Acidente Vascular Cerebral, no âmbito do Sistema Único de Saúde, institui o respectivo incentivo financeiro e aprova a Linha de Cuidados em AVC. Brasília, 2012.

20 Cincura C, Pontes-Neto OM, Neville IS, Mendes HF, Menezes DF, Mariano DC, et al: Validation of the National Institutes of Health Stroke Scale, modified Rankin Scale and Barthel Index in Brazil: the role of cultural adaptation and structured interviewing. Cerebrovasc Dis 2009;27:119-122.

21 Davies PM: Passos a seguir: um manual para o tratamento da hemiplegia no adulto baseado no conceito de K e B Bobath. São Paulo, Manole, 1996.

22 Morris PE, Goad A, Thompson C, Taylor K, Harry B, Passmore L, et al: Early intensive care unit mobility therapy in the treatment of acute respiratory failure. Crit Care Med 2008;36:2238-2243.

23 Shah S, Vanclay F, Cooper B: Improving the sensitivity of the Barthel Index for stroke rehabilitation. J Clin Epidemiol 1989;42:703-709.

-24 Bernhardt J, Dewey H, Thrift A, Donnan G: Inactive and alone: physical activity within the first 14 days of acute stroke unit care. Stroke 2004;35:1005-1009.

25 Panayiotou B, Reid J, Fotherby M, Crome P: Orthostatic hemodynamic responses in acute Stroke. Postgrad Med J 1999;75:213-218.

-26 Hunter AJ, Snodgrass SJ, Quain D, Parsons MW, Levi CR: HOBOE (Head-of-Bed Optimization of Elevation) Study: association of higher angle with reduced cerebral blood flow velocity in acute ischemic stroke. Phys Ther 2011;91:1503-1512.

27 Warlow C, Ogston D, Douglas AS: Deep venous thrombosis of the legs after strokes. Part I - incidence and predisposing factors. BMJ 1976;1:1178-1181.

28 Diserens K, Moreira T, Hirt L, Faouzi M, Grujic J, Bieler G, et al: Early mobilization out of bed after ischemic stroke reduces severe complications but not cerebral blood flow: a randomized controlled pilot trial. Clin Rehabil 2011;26:451-459. 